\title{
Mitochondrial functions in chronic spinal muscular atrophy
}

\author{
J M G O B E R A D O, M G OSALVEZ, C CORTINA, M LOUSA, \\ C R I V A, A N D A G I M E N O
}

From the Service of Neurology, Centro Ramón y Cajal, and Service of Experimental Biochemistry, Clínica Puerta de Hierro, Madrid, Spain

S UMMARY We determined the respiration rate, respiratory control and ADP/O ratios, with different substrates in mitochondria isolated from seven patients with chronic spinal muscular atrophy and compared them with normal human muscle. In all cases studied, a severe alteration of the respiratory control with variable derangement of oxidative phosphorylation was found. Similar findings have been described in other neuromuscular disorders including the so-called "mitochondrial myopathy". We believe that this disturbance of mitochondrial function is non specific and only the hypermetabolic syndrome of Luft could be considered biochemically as a "mitochondrial myopathy", a disorder selectively involving mitochondria of skeletal muscle.

Skeletal muscle mitochondrial function has been reported in a number of different primary neuromuscular disorders including hypermetabolic syndrome, ${ }^{1-3}$ mitochondrial myopathies, ${ }^{4-8}$ specific myopathies, ${ }^{910}$ muscular dystrophy, ${ }^{11} 12$ amyotrophic lateral sclerosis (ALS), ${ }^{13}$ polyneuropathies, ${ }^{1014}$ and the syndrome of chronic progressive external ophthalmoplegia. ${ }^{15}$

Our purpose is to report the biochemical studies of isolated muscle mitochondrias in seven patients with chronic spinal muscular atrophy (CSMA).

\section{Clinical material}

Mitochondrial fractions were isolated on eight muscular biopsy specimens out of seven patients, four males and three females, with CSMA. The patients age ranged from eight to 62 years. Diagnosis was based in all cases upon clinical history, electromyography, and muscular biopsy.

Muscular specimens were obtained from the quadriceps muscle in three patients (cases 1, 5 and 6), gastrocnemius muscle in two (cases 3 and 4), and from the peroneus muscle in the other two (cases 2 and 7). In case 5 muscular specimens

Address for reprint requests: Dr JM Gobernado, Servicio Neurologia, Centro Especial Ramón y Cajal, Carretera de Colmenar, km 9100, Madrid-34, España.

Accepted 20 March 1980 were collected from both quadriceps muscles, one severely affected (left side $5 \mathrm{~b}$ ), and the other better preserved (right side, 5a). In all biopsies the grade of muscular destruction and substitution by fatty and connective tissue was described as slight $(+)$, moderate $(++)$, or severe $(+++)$ as we show in the table.

\section{Methods}

Mitochondrias were isolated from muscle biopsy specimens of 1 to $5 \mathrm{~g}$ (table), essentially by the method of Chappel and Perry ${ }^{16}$ with a variation in the homogenisation procedure. ${ }^{10}$ Oxygen utilisation and oxidative phosphorylation were measured polarographically by previously described methods, ${ }^{10}$ using the Clark Oxygen Electrode. ${ }^{17}$ The Respiratory Control and ADP/O ratios were determined as described by Estabrook. ${ }^{17}$ Glutamate plus malate and succinate were the substrates in all assays. Mitochondrial proteins were determined by methods of Gornall et al. ${ }^{18}$ The concentrations of mitochondrial substrates and other reagents in the assay medium are expressed in the legend of the table.

\section{Results}

The table shows the rates of oxygen uptake of the patient's mitochondrias with the different sub- 


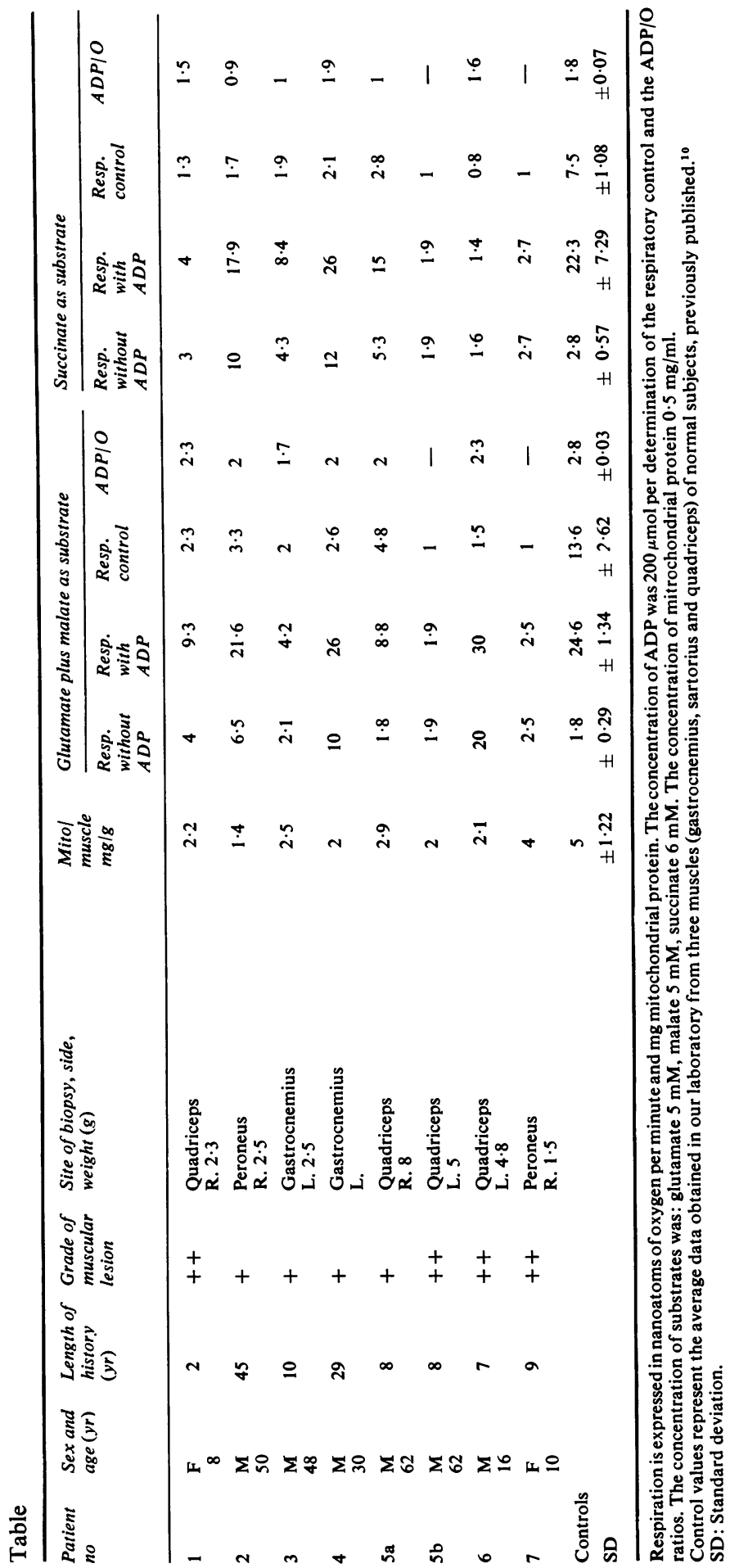


strates as well as values for normal human skeletal muscle mitochondria. Respiration rates for the patient's mitochondria were slightly elevated in the absence of ADP (state 4) and evidently depressed in the presence of ADP (state 3) with both substrates tested.

Mitochondrial Respiratory Control Index (RCI) was low in all cases, except for biopsies $5 \mathrm{~b}$ and 7 in which the lack of Respiratory Control was complete $(\mathrm{RCI}=1)$. The oxidative phosphorylation, ADP/O ratio, was slightly below normal range except for case 4 with succinate as substrate, which was normal. ADP/O ratio is not reported here on cases $5 \mathrm{~b}$ and 7 , since in the absence of a clear transition between state 3 and state 4 this could not be estimated. The yield of mitochondrial protein (mg protein/g fresh muscular tissue) although variable was consistently lower than normal (see the table).

\section{Discussion}

In the present report, studies of oxidative and phosphorylative function of isolated mitochondria from eight muscle biopsies of seven patients with CSMA, showed a notable decrease of respiratory rate in the presence of ADP with two different substrates. As a consequence, the RCI, measured as the ratio of respiratory rate in the presence and after exhaustion of limited amounts of ADP, was also lower than normal. The defect in respiratory rate was observed with both nicotine adenine dinucleotide linked substrates (glutamate plus malate) and with a flavoprotein-linked substrate (succinate). As electrons derived from the oxidation of these substrates enter into the respiratory chain at different sites, the decrease of respiration must be due to a defect in the terminal portion of the oxidative chain or a slowing of phosphorylation at a level common to all three phosphorylation sites. The respiratory rate of the mitochondria in the absence of ADP was higher than the control, indicating also a certain degree of uncoupling. The phosphorylative efficiency ADP/O was slightly decreased, indicating a partial uncoupling.

In a previous case of CSMA, reported by Gimeno $e t a^{10}$ the mitochondrial function showed a decreased respiratory control with conserved phosphorylation. With this data we believe that in CSMA the early stage in mitochondrial disfunction would be the loss of RCI and in a second stage the partial alteration of the coupling system. This abnormality of mitochondrial metabolism was referred to by Luft et $a l^{1}$ as "loosely- coupled" and was reported in other neuromuscular diseases, ${ }^{2}$ 9-12 1415 including the so-called "mitochondrial myopathies." ${ }^{4-8}$

In patients with amyotrophic lateral sclerosis (ALS), with slight muscular lesions, the mitochondrial dysfunction founded by Ioanasescu et $a l^{13}$ was an uncoupled oxidative phosphorylation with normal respiratory control. As the factors responsible for coupling and respiratory control are independent of one another and are not subordinated to a common mode of action, ${ }^{19}$ from the analysis of these biochemical disturbances it may be deduced that the pathogenesis of these two forms of spinal denervation, ALS and CSMA, is different.

In our cases there seemed to be a close relationship between the severity of the histological changes and the altered mitochondrial function (table). This relationship is much more evident in case 5 (biopsies a and b) in which the severity of the mitochondrial dysfunction was higher in the worse histologically-affected muscle. This relationship has been observed before in other neuromuscular diseases. 132021

We believe that the disorders of mitochondrial function reported in the different neuromuscular diseases including the so-called "mitochondrial myopathy," are non specific and that only the hypermetabolic syndrome reports by Luft et al and Haydar et $a l^{2}$ could be considered as a "mitochondrial myopathy," a disorder selectively involving mitochondria of skeletal muscle.

\section{References}

1 Luft R, Ikkos D, Palmieri G, Ernster L, Afzeluis B. A case of severe hypermetabolism of nonthyroid origin with a defect in the maintenance of mitochondrial respiratory control: A correlated clinical, biochemical, and morphological study. J Clin Invest 1962; 41:1776-804.

2 Haydar NA, Conn HL, Afifi A, Wakid N, Ballas S, Fawaz K. Severe hypermetabolism with primary abnormality of skeletal muscle mitochondria. Functional and therapeutic effects of chloramphenicol treatment. Ann Intern Med 1971; 74: 548-58.

3 Di Mauro S, Bonilla E, Lee CP, Schotland L, Scarpa A, Conn H, Chance B. Luft's disease. Further biochemical and ultrastructural studies of skeletal muscle in the second case. J Neurol Sci 1976; 27:217-32.

4 Van Wijngaarden GK, Bethlem J, Meijer AEFH, Hulsmann WC, Feltkamp CA. Skeletal muscle disease with abnormal mitochondria. Brain 1967; 90:577-92.

5 Hulsmann WC, Bethlem J, Meijer AEFH, Fleury 
P, Schellens JPM. Myopathy with abnormal structure and function of muscle mitochondria. J Neurol Neurosurg Psychiat 1967; 30:519-25.

6 Spiro AJ, Prineas JW, Moore CL. A new mitochondrial myopathy in a patient with salt craving. Arch of Neurol 1970; 22:259-69.

7 Schotland DL, Di Mauro S, Bonilla E, Scarpa A, Lee CP. Neuromuscular disorder associated with a defect in mitochondrial energy supply. Arch of Neurol 1976; 33:475-79.

8 Morgan-Hughes JM, Darveniza P, Kahn SN, Landon DN, Sherratt RM, Land JM Clark JB. A mitochondrial myopathy characterized by a deficiency in reducible cytochrome b. Brain 1977; 100:617-40.

9 Bethlem J, Van Gool J, Hulsmann WC, Meijer AEFH. Familial non-progressive myopathy, with muscle cramps after exercise. A new disease associated with cors in the muscle fibres. Brain 1966; 89:569-88.

10 Gimeno A, Trueba JL, Blanco M, Gosalvez $\mathbf{M}$. Mitochondrial functions in five cases of human neuromuscular disorders. $J$ Neurol Neurosurg Psychiat 1973; 36:806-12.

11 Ionasescu V, Luca N, Vuia $O$. Respiratory control and oxidative phosphorylation in the dystrophic muscle. Acta Neurol Scand 1967; 43:564-72.

12 Worsfold M, Park DC, Pennington RJ. Familial "mitochondrial" myopathy. A myopathy associated with disordered oxidative metabolism in muscle fibres. Part 2. Biochemical findings. $J$ Neurol Sci 1973; 19:261-74.

13 Ionasescu V, Luca N, Vuia O, Popa V. Respiratory control and oxidative phosphorylation in the denervated muscle of patients with amyotrophic lateral sclerosis. Biochemical comparison with diabetes mellitus. Acta Neurol Scand 1968; 44: 440-56.

14 Meijer AEFH. Morphologie, histochemie und biochemie mitochondrialer skelettmuskelkrankheiten. Acta histochem, suppl. 1972; 12:333-4.

15 Black JT, Judge D, Demers L, Gordon S. Raggedred fibres. A biochemical and morphological study. J Neurol Sci 1975; 26:479-88.

16 Ernster L, Nordenbrand K. Skeletal muscle mitochondria. In: Methods in Enzymology, New York: Academic Press. 1967; 10:86-94.

17 Estabrook RW. Mitochondrial respiratory control and the polarographic measurement of $\mathrm{ADP} / \mathrm{O}$ ratios. In: Methods in Enzymology. New York: Academic Press. 1967; 10:41-7.

18 Gornall AG, Bardawil CJ, David MM. Determination of serum proteins by means of the biuret reaction. J biol Chem 1949; 177:751-66.

19 Azzone GF, Olofsson EO, Ernster L, Luft R, Szabolesi G. Studies on isolated human skeletal muscle mitochondria. Exp Cell Res 1961; 22: 415-36.

20 Peter JB, Worsfold M. Oxidative phosphorylation and calcium transport by sarcotubular vesicles in myotonic dystrophy. Biochem Med 1969; 2:45760.

21 Peter JB, Stempel K, Armstrong J. Biochemistry and electron microscopy of mitochondria in muscular and neuromuscular diseases. In: Canal $\mathbf{N}$, Scarlato G, and Walton JN eds. Muscle Disease (Proceedings of an International Conference on Muscle Disease, Milán 1969) International Congress Series, no 119. Amsterdam: Excepta Medica, 1970; 228-35. 